would then be equidistant, which would furnish data for a more exact determination of the mean temperature.

Perhaps the most interesting part of the Report is what relates to the wind which is discussed with no little ability and fulness. The results establish beyond doubt that the wind blows more frequently from $\mathrm{N}$. and N.W. than from any other directions, and that these are especially the directions from which winds of high velocity come. This is strikingly shown by the fact that 75 per cent. of all the high winds which occurred during 1879 came from $N$. and N.W. The N, and N.W. winds prevail from November to March, and S. and S.E. winds from May to August, the other months being transitional; and with reference to these S. and S.E. summer winds it is clearly shown that they blow with a much less absolute velocity than do the N. and N.W. winds of the winter months.

Of almost equal importance are the facts of the rainfall. The amount for 1879 was 58.98 inches, the rainiest months being May, June, September, and October, and the driest, November, December, January, July, and August. The rainfall is sorted according to the direction of the wind with which it fell; and the highly interesting results are arrived at that the greater number of rainstorms come from N. and N.W., that the heaviest rains come with N.W. winds, and that in no season are the S. and S.E. winds, not even in summer when they are the predominating winds, accompanied with the maximum rainfall as compared with other wind-directions. The rainfall partitioned in percentages according to the winds with which it fell were N. I8, N.E. 9, E. 9, S.E. 5, S. 7, S.W. 3, W. I7, and N.W. 32, there falling thus 67 per cent. of the whole rainfall with N., N.W., and W. winds.

Among the changes it is proposed by Prof. Mendenhall to be introduced are improved hygrometric observations, which were evidently not trustworthy for 1879 ; observations of earth-temperatures down perhaps to a depth of 40 feet; an extension of the anemometrical observations ; observations of variations in the velocity of sound under different meteorological conditions, the data being obtained from the time-gun, which is fired at noon daily; and a systematic investigation of the phenomena of earthquakes.

But what is urgently required in developing the meteorology of Japan is, beyond all question, the establishment of a network of stations over the Islands equipped with trustworthy instruments. The sub-tropical situation of Japan between the largest continent and the largest ocean of the globe is, from a meteorologist's point of view, unique; and the report now under review points to meteorological peculiarities in its climate of the highest interest. A satisfactory statement of its climatic peculiarities is, as our readers are aware, a desideratum; and the information which could not fail to prove of the highest utility to the Japanese, and is certain to cast important lights on the meteorology of Asia and the Paeific, and particularly on the meteorology of this ocean about latitude $33^{\circ}$, south to which the islands extend, can be furnished from no other source than from a network of meteorological stations overspreading Japan.

\section{MINERAL STATISTICS OF VICTORIA}

FOR some years past the yield of gold in the colony has been steadily decreasing. In 1868 the quantity of the precious metal obtained from alluvial deposits amounted to $1,087,502$ ounces, and from quartz-veins 597,416 ounces, making in all $1,684,918$ ounces of gold. Last year the quantities were respectively - alluvial, 293,310; quartz, 465,637: making a total of 758,947 ounces. The comparatively rapid diminution in the supply from alluvial sources is quite intelligible, as these would necessarily be soonest exhausted, though it is important to observe that in 1879 for the first time for eleven years the return from this source shows a decided advance on that of the preceding year, which is attributed to a better supply of water for sluicing operations, and to the opening up of deep mining ground. It is to quartzmining, however, that the colony must look for the further development of her gold-fields. There has been a gradual decline in the yield from quartz-mines since I872, when the amount obtained was 691,826 ounces. But the Secretary for Mines in his recent report speaks hopefully of the probable future of this important industry. Up to the end of 1879 the total quantity of gold raised in Victoria is estimated to have been 48,7 I9,930 oz. II dwts., valued at $194,879,722 l$. The proportion of gold in the quartz varies considerably in different districts. Thus, last year at Castlemaine the average yield of each ton of quartz was 5 dwts. 18.45 grs., while in Gippsland it amounted to 1 oz. 2 dwts. 18.66 grs. The quartz of the latter locality is by much the most auriferous in the colony. The decrease in the supply of gold has been accompanied by a falling off in the number of miners. The men who found employment in gold mining in 1874 was $45,15 \mathrm{I}$; last year they numbered 37,553 , which was an increase, however, of 917 over the number for 1878 . The mining population includes an industrious and unpopular contingent of Chinamen, who last year amounted to $9, \mathrm{I} 10$, or 528 fewer than in the previous year. Taking the total annual yield of gold and dividing its value among the miners employed, the earnings of an alluvial miner are rated last year at $48 l$. IOs. $1 \frac{1}{2} d$. per annum., while those of the quartz miners are given as $118 l .8 s .7 d$. Deep mining in quartz reefs continues to make propress, and the mines are becoming every year deeper. Some shafts are now more than 2,000 feet deep. The revenue derived by the colony from the gold districts amounted last year to 15,641 . 16s. $9 d$., being a slight advance on that of 1878 .

\section{PHYSICS WITHOUT APPARATUS}

II.

A MONGST the elementary principles of mechanics $\mathrm{A}_{\text {which are capable of easy illustration without }}$ special apparatus is that of the centre of gravity. In every solid mass a point can be found such that the resultant of all parallel forces acting on the individual particles passes through it, and such forces balance themselves around this point. The gravitation-force of the earth is exerted towards its centre, but this being 4,000 miles away, the individual forces acting on the separate particles of a body on the earth's surface may be regarded as parallel forces. Hence the centre of the parallel gravitation-forces is termed the centre of gravity. If the centre of gravity be supported, that is to say, if the resultant force be met by an equal and opposite force of resistance, then the body will not fall. The leaning tower of Pisa does not fall because, in the first place, the mortar is strong enough to bind the masonry into a substantial whole, and, in the second place, because the obliquity of the inclination of the tower is not so great as to throw the centre of gravity beyond the supporting base. A vertical plumb-line dropped down from the centre of gravity of the tower would meet the ground inside the base. It is very easy to irnitate the leaning tower by taking a common wooden roller and sawing off a piece with oblique ends. The toys which are sold under the name of the Toy Blondin also illustrate the principle of the centre of gravity. A metal figure slides or walks down a stretched string, being kept upright by means of a weight fixed to the end of the rod held in the hand of the figure, thus causing the centre of gravity of the whole to fall below the point of support. A simple way of showing the same thing with improvised material is illustrated in Fig. 3. A couple of forks are stuck into a cork. 
Their weight being considerable, the centre of gravity of the combination is below the cork, and if the cork be placed on the tip of the figure or on the lip of a winebottle, it will stand there securely even while the bottle is

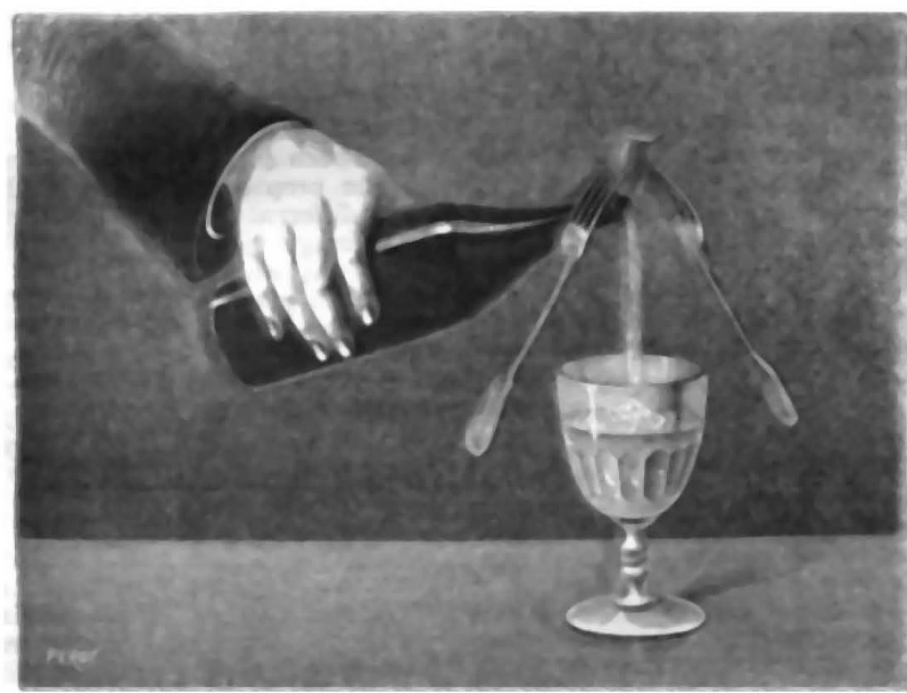

FIG. 3.

cmptied. M. Tissandier has revived another illustration of the same principle which is capable of evoking roars of laughter at a dinner-table. If a dish of snipe has been served up the head with its long beak may be fixed in a

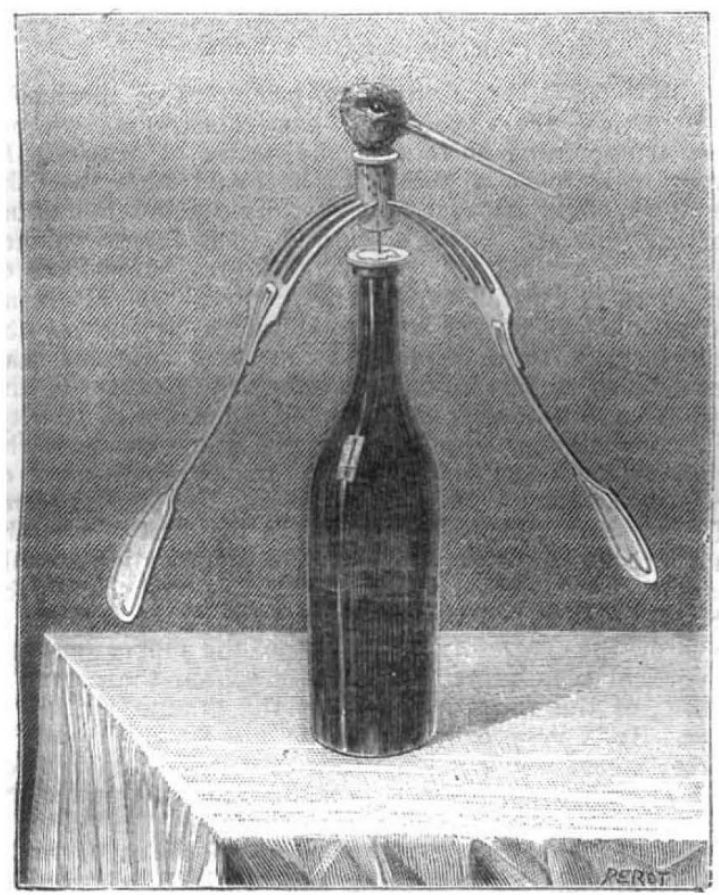

ris 4 .

cork; and then, two forks being thrust into the sides of the cork and a needle having been fixcd into the lower end of it, the cork can be balanced upon a coin laid on the top of a wine-bottle, and can be spun slowly round while the snipe's head nods at the various members of the company in turn, and finally stops opposite one of them (Fig. 4).

A pretty mechanical toy formerly sold in many shops, but now rather rarely met with, is explained upon the principle laid down above. Two small wooden figures with large feet, and holding a couple of poles palanquin-wise between them, are set at the top of a flight of toy stairs. They descend performing summersaults over one another. Fig. 5 shows how the two figures are set at starting. The poles which they grasp are in reality glass tubes plugged at the ends and containing a small quantity of mercury. The figures are themselves made of very light wood, and the quantity of mercury is adjusted to a nicety, so that its position in the tubes determines the position of the centre of gravity of the combination. Fig. 6 shows the position of the mercury in the end $a$ of the tube. At this stage of the movement the figure marked $\mathrm{R}$ is still standing on the topmost step. The other figure, $\mathrm{S}$, is descending, as shown by the arrow. The position of the figure $S$, with the feet foremost, is determined by light silk threads which connect the shoulders of $\mathrm{R}$ with those of $\mathrm{S}$, and in this position $\mathrm{S}$ has the advantage in weight over the counterbalancing mercury at $a$, hence $\mathrm{s}$ continues to descend until the tubes have passed the position in which they are level. Once past this position the mercury rurs down from $a$ to $b$ and brings down $\mathrm{s}$ firmly on to his feet on the second step. At this juncture the arrangement of the various parts will be that indicated

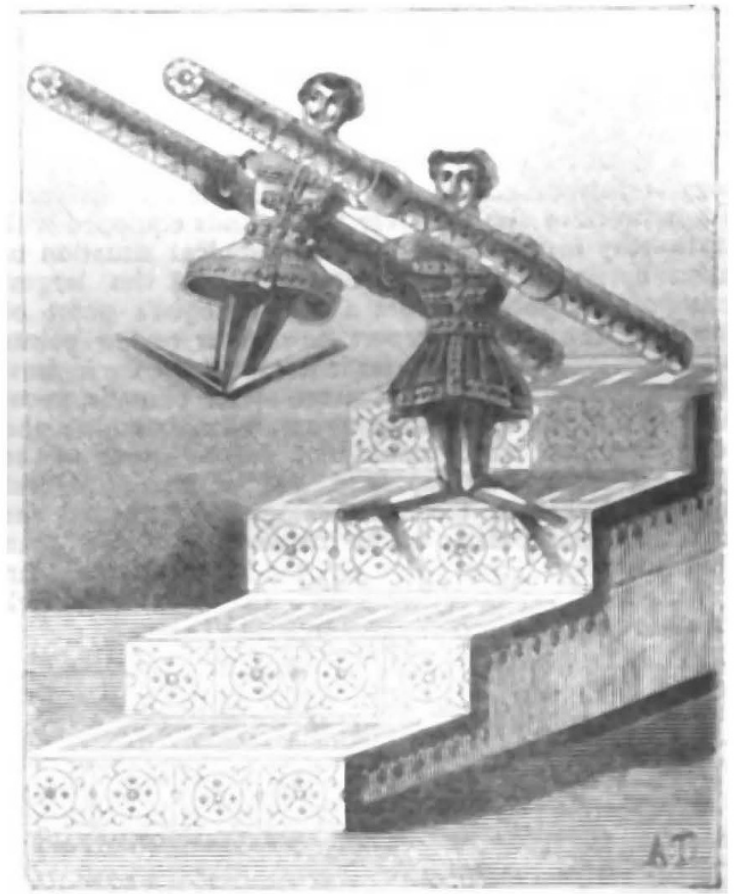

FIG. 5.

in Fig. 7. The hands of $\mathrm{s}$ now become the pivot about which the poles can turn and the mercury in $b$ is collected right in the bottom of the tube, where it has the greatest leverage. The feet of $R$ (which are 
proportionally the heaviest part of him) are near to s, and his centre of gravity is therefore comparatively ncar to the pivot about which the combination is going to revolve. Hence while $b$ sinks, $\mathrm{R}$ rises, and as he performs his

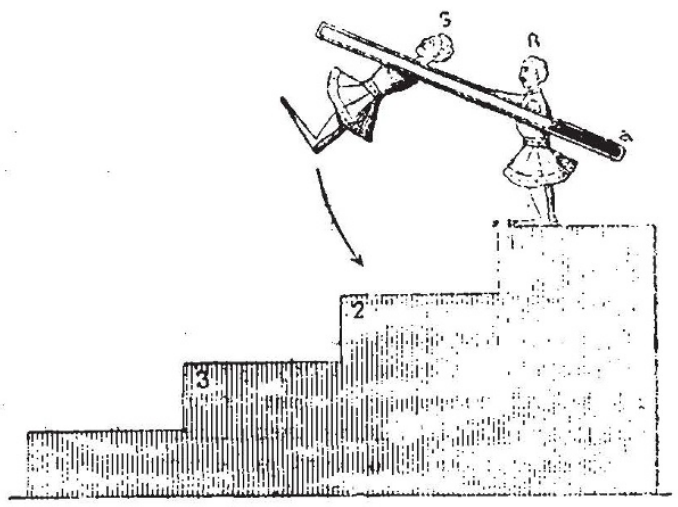

Fig. 6.

flight through the air over the head of $\mathrm{S}$ the silken strings gradually bring his feet forward until at last he has turned them forward so much that he has the greater leverage over the counterbalancing mercury at $b$ and

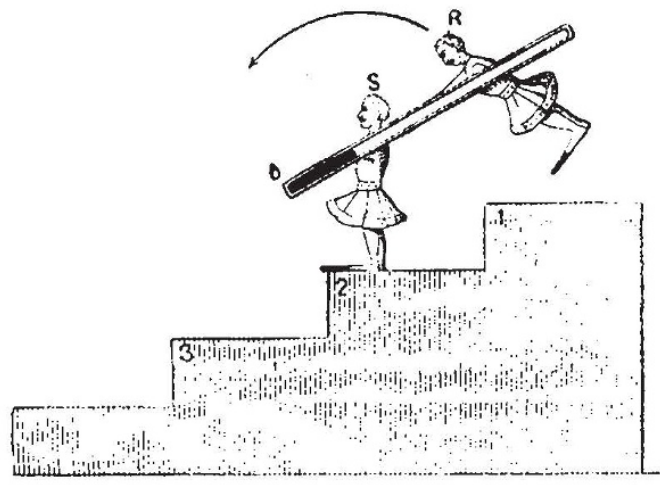

Fic. 7 .

descends ready to take his stand on the third step. In this way the two manikins vault over one another's heads until they have descended from top to bottom of their tiny flight of stairs.

\section{( $T$ o be continued.)}

\section{NOTES}

THE French deep-sea exploring expedition off the North Coast of Spain in the Bay of Biscay, last month, appears to have becn very successful, and to bave fully confirmed the great reputation formerly earned by our neighbours in similar undertakings throughout the wide ocean. No less than $\mathrm{IO}_{3}$ sounding; were taken. The fauna agrees with that which was obscrved in the Forcupine cruise of 1870 along the western coasts of Spain and Portugal; and there are corresponding inequalities in depth. We understand that, with the approval of the French Commission, Dr. Gwyn Jeffreys will give an account of this expedition at the Swansea meeting of the IBritish Association. The Paris report in the Times of August 5 is not quite correct.

Tre American Association for the Advancement of Science meets this year at Boston, on the same day as our own does at Swansea, August 25. From the Local Committee's circular, which has leen sent us, it is evident that a "good time" is in store for those who attend the meeting, and they are likely to be many. It seems to us that the organisation of the American Association is much better than ours, though it will be seeh from last weck's NATURE that the Swansea Committec have taken grcat pains to give the British $\Lambda$ ssociation an agreeable reception. The Boston Local Cummitlee contains many well-known names, and is subdivided into a Committee-at-Large, Reception Committee (which includes the names of numerous ladies, headed by Mrs. Louis Agassiz), Committees on Finance, Railrotds, Lotels and Lougings, Roomsfor Mcetings, Mails, Express, and Telegraph, and Excursions. On these committees we find such namres as Ralph Waldo Emerson, Asa Gray, Oliver Wendell IIolmes, Henry W. Longfellow, A. Graham Bell, A. Agassiz, and many others eminent both in science and literature. The arrangements for excursions and receptions seem admirable, and the savants will have a terrible round of pleasure to undergo. Among other provisions by the Local Committee is a daily, free public luncheon between the morning and afternoon sectional zueetings, for the purpose of keeping the members together. The circular contains all information about hotels and lodgings, receptions, excursions, meetings, \&c., and ample provision has been made in the varipus rooms for experiments and illustrations. The rooms will be connected by telephone with each other, with the hotels, and with the general telephone circuit of Boston and Cambridge. Indicators in each of the sectional rooms, as well as in the secretary's room and in the hotel selected for head quarters, will show at any moment what papers are under discussion in each of the sections. Among the public addresses to be given during the meeting are those of the retiring president, Prof. G. F: Barker, the vice-president of Section A, Prof. Asaph Hall, and the vice-president of Section B, Mr. Alexander Agassiz.

Tre Annual Meeting of the British Medical Association was opened at Cambridge on Tuesday, under the presidency of Prof. Humphry.

Trie Institution of Mechanical Engineers had a very successful meeting last week at Barrow-in-Furness. Every facility was afforded the members for inspecting the many objects of engrincering interest in Barrow and its vicinity. The papers read werc all of more or less technical interest.

ON Thursday last the Anthropological Congress was opened at Berlin in the presence of the Crown Prince and Princess of Germany and of many distinguished literary and scientific men. Prof. Virchow delivered an eloquent speech. Ir. Schliemann afterwards gave an account of his discoveries and excavations. On Monday a banquet was given in honour of Dr. Schliemann and Prof. Nordenskjöld, who, on Tuesday, were entertained by the Crown Prince.

Is connection with the vote for the British Museum on Monday there was some talk as to the organisation of that institution and of the new Natural History Muscum. Mr. Walpole spoke hopefully of the early transference of all the collections destined for the South Kensington buildings, while Mr. Story-Maskelyne, tenderly remembering his former colleagues, advocated the crection of houses for the officials. There was a good deal of vague and unsatisfactory talk about the distribution of duplicates to provincial muscums. This is evidently a mattcr that requires clcaring up, and it might be well to take means to decide once for all what are duplicates and what would be the best method of disposing of them. Mr. $\mathrm{M}^{\prime} \mathrm{Cullagh}$ Torrens thought there was great room for reform in the method of appointing the Trustees of the British Museum, who are far from being reprecentative; there shonld, be thinks, be a larger infusion of the scientific element among them.

A CORRESPONDENT sends us some notes as the result of a visit to the 13clgian National Kxhibition at Brusscls. The total 